\title{
KEMER SIKMA POLITIKALARINDAN MALİ TUZAĞA: AB ÇEVRE ÜLKELERİ BAĞLAMINDA BİR İNCELEME
}

\section{Doç. Dr. Zeliha GÖKER* Servet AKYOL ${ }^{* * *}$}

\begin{abstract}
Öz:
$\mathrm{Bu}$ çalışmanın amacı daraltıcı politikaların teorik temellerini ortaya koymak, günümüz koşullarında bu politikaların başarısını ve $\mathrm{AB}$ 'de çevre ülkeler için mali tuzak riskini değerlendirmektir. 2008 yılında ortaya çıkan küresel finansal kriz sonrasında gelişmiş ve gelişmekte olan ülkelerin önemli bir bölümünde krizin etkilerini hafifletmek ve daha da derinleşmesini engellemek için kurtarma paketleri ve harcama artış//vergi indirimini içeren canlandırma paketleri uygulanmıştır. Kurtarma ve canlandırma paketlerinin uygulanması bütçe açığı/GSYIH ve borç/GSYIH gibi kamu kesimi dengelerinin kötüleşmesine yol açmıştır. Bu durumu ortadan kaldırmak için canlandırma paketlerinin yerini kemer sıkma politikaları almıştır. Ancak günümüzde düşük büyüme oranlarının olduğu bir durumda sıkı maliye politikası uygulamaları kendi kendini besleyen bir süreçle mali tuzak riskini gündeme getirmiştir. Bu durum özellikle Avrupa Birliği’nin çevre ülkelerinin kriz sonrasındaki ekonomik performanslarında gözlenmektedir.
\end{abstract}

Anahtar Sözcükler: Maliye Politikası, Kemer Sıkma Politikası, Mali Tuzak, AB Ülkeleri

JEL sinıflandırmasi: E62 H12 O52

* Doç. Dr.,Akdeniz Üniversitesi, İ̈BF, Maliye Bölümü, zgoker@akdeniz.edu.tr

** Arş. Gör., Akdeniz Üniversitesi, İIBF, Maliye Bölümü, servetakyol@ yahoo.com 


\title{
FROM FISCAL AUSTERITY POLICIES TO FISCAL TRAP: A REVIEW IN THE CONTEXT OF EU PERIPHERY COUNTRIES
}

\begin{abstract}
:
The objective of this study is to discuss the theoretical basics of contractionary economic policy and to evaluate the sucess of these policies under today's circumstances and fiscal trap risk for periphery countries of EU. After the post 2008 küresel financial crisis in many of developed and developing countries bailout plans and stimulus packages including spending rise/tax cut have been applied in order to ease the effects of the crisis and to prevent the effects get deeper. Implementing the bailout and stimulus packages caused public sector balances get worse like public sector deficit/GDP and public debt/GDP. In order to eliminate this situation stimulus packages are replaced by austerity policies. But today under the circumstances in which there are low growth rates tight fiscal policy put down fiscal trap risk on the agenda with a process that feeds itself. This condition is especially observed in the post crisis economic performances of periphery countries of the EU.
\end{abstract}

Key Words: Fiscal Policy, Austerity Policy, Fiscal Trap, EU Countries

JEL classifications: E62 H12 O52

\section{GİRIŞ}

ABD’nin yanı sıra İngiltere ve diğer gelişmiş ülkelerde ortaya çıkan 2001-2007 yılları arasındaki konut balonunu besleyen asıl unsur, ABD'de izlenen gevşek para politikasına dayanan ucuz krediler olmuştur. Ancak bu dönemde kredilerin dış fon kaynağı daha önceki dönemlerin aksine gelişmiş ülkeler değil, 1997-98 Asya krizinden sonra döviz kuru krizlerine karşı önlem olarak döviz rezervi biriktirmek zorunda kalan yoksul ülkelerdir. 2007 sonunda likidite yetersizliği ile başlayan kriz, küresel bir krize dönüşmüştür. Çünkü bir yandan ABD’nin "menkul kıymetleştirdiğì" kâğıtlar gelişmiş ülkelerin bankaları tarafından yoğun talep görmüştür. Diğer yandan ise likidite yetersizliğinin banka kredilerine yansımasıyla üretim hızla düşerken, azalan tüketici talebi üretimi olduğu kadar ihracatı da olumsuz etkileyerek, krizin hızla Almanya, Japonya, Çin ve diğer gelişmekte olan ihracatçı ülkelere yayılmasına yol açmıştır.

Krize devletler para ve maliye politikası ile müdahale etmiştir. Para politikası ile faiz oranları hızla sıfıra yakın düzeylere düşürülerek bankalar açısından fon maliyeti asgariye indirilmiş, likidite kıtlığını karşılamak için Merkez Bankaları büyük miktarda kamu kredisi vermiş, önemli ölçüde kamu 
fonları bankalara aktarılarak ve banka mevduatları garanti kapsamına alınarak ödeyememe riski azaltılmıştır. Maliye politikası ile de özel kesim talebindeki azalma kamu harcamaları ile desteklenerek, üretimdeki azalma ve işsizlik oranlarındaki artış yavaşlatılmaya çalışılmıştır.

2008 y1lından günümüze, özellikle gelişmiş ekonomilerde maliye politikası uygulamalarına ilişkin üç farklı dönemden söz edilebilir. Birinci dönem 2008-2010 yılları arasına karş11ı gelmektedir. Bu dönem, kriz sonrası dünya ekonomilerinin daha önce yaşadığı Büyük Buhran döneminin bir benzerinin yaşanmaması için kurtarma paketlerinin ve harcama artışı/vergi indirimini içeren canlandırma paketlerinin uygulandığı dönemdir.

İkinci dönem 2010 y1lından sonra ortaya çıkmıştır. Bu dönemde artan kamu borçları ve bütçe açıkları nedeniyle canlandırma paketlerinin yerini kemer sıkma politikaları (austerity policy) almıştır. Maliye politikası ekonomik faaliyetleri desteklemek yerine borçların azaltılmasına yönlendirilmiş, mali konsolidasyon yani mali dengede iyileşmeyi hedefleyen daraltıcı politikalar ön plana çıkarılmıştır. Oysa kriz finansal sektörden kaynaklanmıştır ve kriz nedeniyle kamu borçları artmış, bütçe dengeleri bozulmuştur (Zezza, 2012). Ancak bu dönemde finansal piyasalara yönelik düzenlemeler yerine kamu sektörüne yönelik daraltıcı politikalar ön plana çıkmıştır.

Kriz sonrasındaki maliye politikası uygulamalarına ilişkin üçüncü dönem ise günümüzde yaşanmaktadır. $\mathrm{Bu}$ dönemin temel özelliği düşük büyüme oranları söz konusu iken sıkı maliye politikası uygulamalarının kendi kendini besleyen bir işleyişle mali tuzak (fiscal trap) sürecine neden olabilecek bir dönem olmasıdır. Tehdit, harcama kesintileri ve/veya vergi artışları ile bütçe açı̆̆ $/$ GSYIH oranının düşürülmesi hedeflenmesine rağmen, bu uygulamanın talebin düşmesine yol açmasıyla hem GSYİH'nın, hem de vergi gelirlerinin azalması sonucu, hedeflenenin aksine bütçe açığı/GSYİH oranının artması, durgunluğun devam etmesi olarak karşımıza çıkmaktadır.

$\mathrm{Bu}$ çalışmanın amacı daraltıcı politikaların teorik temellerini ortaya koymak, günümüz koşullarında bu politikaların başarısını ve $\mathrm{AB}$ 'de çevre ülkeler için mali tuzak riskini değerlendirmektir. Bu çerçevede birinci bölümde küresel kriz karşısında ülkelerin uyguladığı mali canlandırma politikalarından kemer sıkma politikalarına geçiş süreci ele alınmaktadır. İkinci bölümde genişletici mali daralma hipotezi ve hipotezi doğrulayan ülke örnekleri üzerinde durulmaktadır. Üçüncü bölüm durgunluk dönemlerinde uygulanan kemer sıkma politikalarının mali tuzak yaratma potansiyelini incelemektedir. $\mathrm{AB}$ 'de çevre ülkelerde uygulanan kemer sıkma politikalarının başarısı ve bu ülkeler için mali tuzak riski dördüncü bölümün konusunu oluşturmaktadır. Sonuç bölümünde ise genel bir değerlendirme yer almaktadır. 


\section{I) MALI CANLANDIRMADAN KEMER SIKMA POLITIIKALARINA GEÇIŞ}

2010 ve 2011 yıllarında hazırlanan IMF raporları, kriz sonrası iki yılın ekonomilerin toparlanması için yeterli olduğunu savunarak, ülkeler için mali konsolidasyon ihtiyacına işaret etmektedir. Çünkü IMF'ye göre çift dipli durgunluk riski gündemden çıkmış, özel talep sürdürülebilir bir temelde ekonomik iyileşmeyi sağladığından kamu talebi ile değiştirilebilir bir duruma ulaşmıştır. Gelişmiş ülkeler enflasyon baskısını gidermek, mali dengeyi yeniden sağlamak ve aşırı 1sınmadan kaçınmak için mali teşvik/canlandırma politikalarına ara vermek zorundadırlar (Calcagno, 2012:28). Dolayısıyla bu dönemde artan kamu borçları ve bütçe açıkları nedeniyle canlandırma paketlerinin yerini kemer sıkma politikaları almış, maliye politikası ekonomik faaliyetleri desteklemek yerine borçların azaltılmasına yönlendirilmiş, mali konsolidasyon yani mali dengede iyileşmeyi hedefleyen politikalar ön plana çıkmıştır. Ancak söz konusu politika değişiklikleri küresel ekonominin durgunluktan çıktığı ancak cılız bir iyileşmenin sağlandığı, sıfır ya da çok düşük faiz oranları nedeniyle para politikasının etkisinin sınırlı olduğu bir dönemde yapılmıştır.

S1k1 maliye politikaları ile mali konsolidasyonun sağlanabileceğini savunan iktisadi görüş yüksek vergiler ve/veya harcama kesintileri şeklindeki politikaların büyüme üzerindeki dolaylı etkilerine güvenmektedir. S1kı maliye politikaları ile bütçe açıklarının azaltılmasının ve böylece borç/GSYİH oranının düşürülmesinin ekonomiyi canlandırması, büyümeyi uyarması "genişletici mali daralma" hipotezi olarak adlandırılmaktadır. Genişletici etkiler hem arz yönlü hem de talep yönlü ortaya çıkmaktadır (Alesina, 2010:4; Alesine ve Ardagna, 2010:3). Talep yönlü etkiler, daraltıcı politikalar ile yüksek faiz oranlarının düşürülmesi ve uluslararası ticarette ülke payının artırılması ile sağlanmaktadır. Özel sektörün harcama artışını sağlayan faiz oranlarının düşmesidir. Şimdiki mali daralma politikalarıyla gelecekte daha büyük ve daha bozucu mali daralmanın önleneceği ve kamunun borcunu ödeyememe riskinin ortadan kalkacağına ilişkin beklenti kamu borçlanma faizinin düşmesine neden olmaktadır. Böylece faize duyarlı yurt içi yatırım ve tüketim harcamaları teşvik edilirken aynı zamanda paranın değerinin düşmesinin de ticaret dengesinin iyileşmesini sağlayacağı, ihracat artarken, ithalatın azalmasının büyümeyi olumlu yönde etkileyeceği öngörülmektedir.

Düşük faiz oranı bir yandan yatırımcılar için makine teçhizat ya da yeni binalar, araştırma-geliştirme faaliyetleri için borçlanma maliyetini azaltırken, diğer yandan da tasarrufların cazibesinin azalmasına neden olacağı için tüketimi teşvik etmektedir. Dolayısıyla eğer faiz oranlarındaki düşme nedeniyle net ihracatta, yurt içi yatırım ve tüketim harcamalarında meydana 
gelen talep artışı, vergi artışları ve harcama kesintileri nedeniyle ortaya çıkan talep azalışından daha büyük ise bu durumda sıkı maliye politikası ile genişletici etki yaratılmış olmaktadır (Baker, 2010:6). Arz yönlü etkiler ise emek piyasasından kaynaklanmaktadır. Vergi artışlarına dayalı bir mali konsolidasyonun kısa ömürlü olacağından hareketle, daha kalıcı iyileşmeler için kamu istihdamında ve kamu ücretlerinde kesintilerin gerekli olduğu savunulmaktadır (Alesina ve Ardagna, 1998). S1k1 maliye politikaları çerçevesinde kamu istihdamında azalma ve kamu ücretlerinde yapılan indirimler bütün emek piyasasını etkileyerek, çalışmak istediği halde iş bulamayan insanların daha düşük ücretleri kabullenmesine, çalışanların taleplerinin sınırlandırılmasına yol açarak üretim maliyetlerinin düşmesini sağlamaktadır. Böylece düşük birim üretim maliyetleriyle uluslararası piyasalarda rekabet avantajı yaratılarak büyümenin teşvik edileceği ön görülmektedir.

$\mathrm{Bu}$ çerçevede 2010 yılından itibaren ekonomik iyileşme yetersiz ve işsizlik oranları hala yüksek olmasına rağmen mali konsolidasyon için konjonktür yanlı (pro cyclical), daraltıcı maliye politikaları tercih edilerek, istihdama değil mali dengeye öncelik verildiği görülmektedir. $\mathrm{Bu}$ amaçla subvansiyonlar azaltılmış ya da kaldırılmış, ișten çıkarmalar ve ücretlerde kesintiler yapılmış, tüketim vergileri artırılmış, emeklilik ve sağlık hizmetlerinde yeni düzenlemelerin yanı sıra emek piyasalarının esnekliğini artırmaya yönelik işlemlere ağırlık verilmiştir (Ortiz ve Commis, 2013:24-34). $\mathrm{Bu}$ uygulamalarda daraltıcı politikaların genişletici etkilerine güvenilmekle beraber, küresel durgunluk devam ederken, gelişmiş ve gelişmekte olan pek çok ülkenin aynı anda daraltıcı politikalar uygulaması nedeniyle bu politikaların başarılı olması beklenmemektedir. Üstelik bu politikaların durgunluk döneminde uygulanması durumunda ne tür sonuçlar yaratacağına ilişkin yeterli çalışma da mevcut değildir (Semmler ve Semmler, 2013:2). IMF dâhil son dönemde bazı görüşler bu dönemde istikrar politikaların etkili olmadığına, aşırı sosyal maliyetlere neden olduğuna dikkat çekmektedir (Blanchard vd., 2013; Baum vd., 2012).

\section{II) KEMER SIKMA POLITIKKALARININ BAŞARILI OLDUĞU ÜLKELER VE DÖNEMLER}

Genişletici mali daralma hipotezini destekleyen uygulamalar esas olarak küçük ve faiz oranlarının yüksek olduğu ülkelerde, 1980 ve 1990'lı yıllarda görülmektedir. Danimarka (1983-1986), İrlanda (1987-89), Finlandiya (1992-1998) ve İsveç (1993-1998) bu ülkeler arasındadır (IMF, 2010; Perotti, 2011). 
Tablo:1 Daraltıcı Politikaların Genişletici Etkiler Yarattığı Ülke Örnekleri

\begin{tabular}{|c|c|c|c|c|c|c|c|c|}
\hline & \multirow{2}{*}{$\begin{array}{c}\text { Daraltıcı } \\
\text { politikalar } \\
\text { (GSYİH \%) }\end{array}$} & \multirow{2}{*}{$\begin{array}{c}\text { Döviz Kuru } \\
\text { (DK)/ } \\
\text { Para } \\
\text { Politikası }\end{array}$} & \multicolumn{3}{|c|}{ Mekanizmaların kapsamı } & \multicolumn{3}{|c|}{ Etki } \\
\hline & & & Kredibilite & Ücretler & $\begin{array}{l}\text { Reel Döviz } \\
\text { Kuru }\end{array}$ & $\begin{array}{l}\text { Yurtiçi } \\
\text { Talep }\end{array}$ & İhracat & $\begin{array}{l}\text { GSYİH'da } \\
\text { değişim }\end{array}$ \\
\hline $\begin{array}{l}\text { Danimarka } \\
1983-86\end{array}$ & $\begin{array}{l}\text { Harcamalar } \\
\% 4 \text { azaldı, } \\
\text { vergi } \\
\text { gelirleri } \\
\% 4.9 \text { arttı }\end{array}$ & $\begin{array}{l}\text { DK nominal } \\
\text { çapa olarak } \\
\text { kullanıldı }\end{array}$ & $\begin{array}{l}\text { Faiz oranı } \\
\text { \%21'den } \\
\% 11,3 \text { 'e } \\
\text { düştü }\end{array}$ & $\begin{array}{l}\text { Ücretlerin } \\
\text { sinırlanması ve } \\
\text { enflasyon } \\
\text { oranının } \\
\text { düşürülmesi }\end{array}$ & Değerlenme & $\begin{array}{l}\text { Tüketim ve } \\
\text { yatırım } \\
\text { harcamaları } \\
\text { nda artış }\end{array}$ & $\begin{array}{l}\text { Ilımlı } \\
\text { artış }\end{array}$ & $\begin{array}{l}\text { Kısa dönemde } \\
\text { hızlı büyüme, } \\
\text { daha sonra } \\
\text { büyüme hızının } \\
\text { yavaşlaması }\end{array}$ \\
\hline $\begin{array}{l}\text { İrlanda } \\
1987-89\end{array}$ & $\begin{array}{l}\text { Harcamalar } \\
\% 3, \text { vergi } \\
\text { gelirleri } \\
\% 0.1 \text { azald } 1\end{array}$ & $\begin{array}{l}\text { DK nominal } \\
\text { çapa olarak } \\
\text { kullanıldı }\end{array}$ & $\begin{array}{l}\text { Faiz oranı } \\
\% 11,3 \text { 'ten } \\
\% 9,2 \text { 'ye } \\
\text { düştü }\end{array}$ & $\begin{array}{l}\text { Üç taraflı ücret } \\
\text { pazarlığı ve } \\
\text { enflasyon } \\
\text { oranının } \\
\text { düşürülmesi }\end{array}$ & $\begin{array}{l}\text { Ilımlı değer } \\
\text { kaybı }\end{array}$ & $\begin{array}{l}\text { İstikrarlı } \\
\text { tüketim, } \\
\text { yatırımın } \\
\text { başlangıçta } \\
\text { azalması }\end{array}$ & $\begin{array}{l}\text { Yüksek } \\
\text { artış }\end{array}$ & $\begin{array}{l}\text { Önce yavaş } \\
\text { büyüme, daha } \\
\text { sonra hizlı } \\
\text { büyüme }\end{array}$ \\
\hline $\begin{array}{l}\text { Finlandiya } \\
1992-98\end{array}$ & $\begin{array}{l}\text { Harcamalar } \\
\% 0,4 \text { azald } 1, \\
\text { vergi } \\
\text { gelirleri } \\
\% 3.5 \text { arttı }\end{array}$ & $\begin{array}{l}\text { Dalgalı DK } \\
\text { Enflasyon } \\
\text { Hedeflemesi }\end{array}$ & $\begin{array}{l}\text { Faiz oranı } \\
\% 12 \text { 'den } \\
\% 4,8 \text { 'e } \\
\text { düştü }\end{array}$ & $\begin{array}{l}\text { Gelir } \\
\text { politikalarında } \\
\text { anlaşma }\end{array}$ & $\begin{array}{l}\text { Önemli } \\
\text { derecede } \\
\text { değer kaybı }\end{array}$ & $\begin{array}{l}\text { Tüketim ve } \\
\text { yatırım } \\
\text { hızının } \\
\text { azalması }\end{array}$ & $\begin{array}{l}\text { Çok } \\
\text { büyük } \\
\text { artış }\end{array}$ & $\begin{array}{l}\text { Önce büyüme } \\
\text { hızının } \\
\text { yavaşlaması } \\
\text { sonra } \\
\text { hızlanması }\end{array}$ \\
\hline $\begin{array}{l}\text { İsveç } \\
\text { 1993-98 }\end{array}$ & $\begin{array}{l}\text { Harcamalar } \\
\% 3,6 \text { azald } 1, \\
\text { vergi } \\
\text { gelirleri } \\
\% 4.8 \text { arttı }\end{array}$ & $\begin{array}{l}\text { Dalgalı DK } \\
\text { Enflasyon } \\
\text { Hedeflemesi }\end{array}$ & $\begin{array}{l}\text { Faiz oranı } \\
\% 8,6 \text { 'dan } \\
\% 5 \text { 'e düştü }\end{array}$ & $\begin{array}{l}\text { Ücretlerde düşük } \\
\text { artış ve sosyal } \\
\text { yardımlarda artış }\end{array}$ & $\begin{array}{l}\text { Büyük bir } \\
\text { devalüasyon }\end{array}$ & $\begin{array}{l}\text { Güçlü } \\
\text { daralma }\end{array}$ & $\begin{array}{l}\text { Çok } \\
\text { büyük } \\
\text { artış }\end{array}$ & $\begin{array}{l}\text { Önce büyüme } \\
\text { hızının } \\
\text { yavaşlaması } \\
\text { sonra } \\
\text { hızlanması }\end{array}$ \\
\hline
\end{tabular}

Kaynak: Boyer, 2012:299

$\mathrm{Bu}$ ülkelerin koşullarına bakıldığında üç temel mekanizmanın öne çıktığı görülmektedir. Bunlardan ilki, yüksek nominal faiz oranlarının önemli ölçüde düşürülmesiyle ortaya çıkan kredibilite etkisidir. Söz konusu ülkelerde daraltıcı politikalar kullanılarak belirtilen dönemlerde nominal faiz oranları önemli ölçüde aşağıya çekilmiştir. Fakat bu başarıda kamu maliyesindeki iyileşmeler kadar anti-enflasyonist politikaların katkısı da önemlidir. Böylece düşük faiz oranlarının uyardığı dayanıklı tüketim malları talebindeki artış, kamu harcamaları azalırken tüketim harcamalarının artmasını sağlamıştır. İkinci mekanizma, birim emek maliyetini düşürmek için ücret düzenlemelerini içeren gelir politikasıdır. Ancak, örneğin ücret artışları yerine gelir vergisi indiriminin kabul edilmesi niteliğindeki bu düzenlemeler, piyasa mekanizması aracılığı ile değil, ulusal rekabet gücünü artırmayı amaçlayan toplumsal bir anlaşma ile olmuştur. Son mekanizma ise, yurtiçi talep daralmasını telafi edecek büyüklükte ihracat artışını teşvik eden devalüasyon uygulamasıdır. Bu şekilde rekabet avantajı sağlayan devalüasyon ancak küçük ülkeler için söz 
konusu olabilir, aksi halde ticaret ortaklarının misillemeye gitmesi durumunda bu avantaj ortadan kalkacaktır (Boyer, 2012:298).

$\mathrm{Bu}$ ülkelerin daraltıcı politikalar uyguladığı dönem, dünya ekonomisinin sağlıklı bir şekilde büyüdüğü döneme karşılık gelmektedir. Bu durum uluslararası ticaret payı yüksek bu küçük ülkeler için önemli bir avantaj sağlamıştır çünkü dış talebin ülkedeki harcama kesintisi veya vergi artışına duyarlılığ1 yoktur. Ancak 1990'lı yıllardan farklı olarak günümüzde faiz oranları çok düşüktür. $\mathrm{Bu}$ nedenle faizlerin düşürülmesi yoluyla özel harcamaların uyarılması çabası sınırlı bir yarar sağlamaktadır. Diğer yandan tüm ülkelerin emek maliyetlerini düşürerek daha çok ihracat yapabilme çabası ise küresel durgunluk döneminde hem "komşuyu" hem de "evdeki çalışanları" fakirleştiren bir uygulama olarak beklenen etkinin tersi bir sonuç yaratmaktadır. Dolayısıyla 1990'lı yıllardan çok farklı koşulların varlığı nedeniyle daraltıcı politikaların bu dönemde genişletici etkiler yaratması mümkün görünmemektedir (Baker, 2010; Jajadev ve Konczal, 2010).

\section{A) Kriz ve Kemer Sıkma Politikalarının İlişsisi}

Kriz ve kemer sıkma politikalarının ilişkisinin odağında krizin finansal sektörden kaynaklanmasına karşın, kurtarma paketleri ile krizin yükünün kamu maliyesine yüklenmiş olması yer almaktadır. Üstelik bu yeni durum karşısında kamu maliyesi artan açık ve borç yükünün finansmanı için kurtarılan finansal sektöre bağımlı hale gelmiştir (Zezza, 2012: 38; Albo ve Evans, 2012:310). Kriz kamu harcamalarında artışları ve/veya vergi indirimlerini içeren mali teşvik paketlerinin yanı sıra farklı kanallardan bütçe dengesini ve kamu borçlarını etkilemiştir. Özellikle gelişmiş ülkelerde kamu borçlarının artması krizin doğrudan bir sonucu olarak ortaya çıkmıştır. Sorunlu finansal kuruluşların devlet tarafından kurtarılması amacıyla özel sektör borcunun kamu borcuna dönüştürülmesi kamu borçlarını artırırken, bu kurtarma paketlerinin ekonomiyi canlandırıcı etkisi sınırlı olmuştur. Kamu açıklarının ve kamu borçlarının artmasının sebeplerinden bir diğeri ise otomatik dengeleyicilerdir, özellikle ekonomik faaliyetlerin azalmasıyla kamu gelirleri azalırken, işsizlik ödemesi gibi sosyal harcamaların artması bütçe dengesi ve kamu borçlarını olumsuz etkilemiştir. Dolayısıyla krizin nedeni kamu harcamalarının veya kamu bütçe açığının aşırı büyümesi değildir, tersine kriz nedeniyle pek çok ülkede bütçe açıkları artmış ve/veya kamu borcu/GSYİH oranları yükselmiştir. Ancak kemer sıkma politikaları ile sanki sorun kamu sektörüymüş gibi yanlış bir alg1 yaratılarak sosyal güvenlik harcamalarında, sağlı harcamalarında kesintiler için zemin hazırlanmıştır. Diğer yandan krizin sorumlusu olan finans sektöründe gerekli reform ihtiyacı ise göz ardı edilmiş̧ir (Palley, 2009). 
Kriz sonrasında tekrar gündeme gelen kemer sıkma politikaları aslında uzun bir geçmişe sahiptir. IMF ve DB gözetimi altında uygulanan bu tip politikalar bir ödemeler dengesi problemi ortaya çıktığında gündeme gelmekte, yapısal reformlar karşılığında IMF'nin kısa vadeli kredi sağlamasıyla dengesizliklerin giderilmesi amaçlanmaktadır. Dünya ekonomisinin 1980 sonrasındaki neoliberal evresinin en dikkat çekici özelliği sermaye ve emek arasındaki dengelerin emek aleyhine değişmesi ve gelir dağılımının bir bütün olarak sermaye lehine bozulmasıdır. Bu nedenle kemer sıkma politikalarına yönelik eleştirilerin arka planı esas olarak neoliberal politika uygulamalarına dayanmaktadır. Zira bu süreçte kurtarma paketleri ile finansal sektörün kayıpları tüm topluma dağıtılırken, krizin yarattığı işsizlik ve istihdam kayıplarını telafi etmek yerine kemer sıkma politikaları ile işten çıkarmaları ve ücretlerde azalmayı daha fazla artırmak, emek aleyhine uygulamaların bir göstergesidir. Bu anlamda, 2008 krizinde uluslararası kuruluşların işbirliği ile, hükümetler bankaların son borç merci olarak davranırken, işçileri korumak ve istihdamı teşvik etmeye yönelik son istihdam merci olarak davranmamıştır. $\mathrm{Bu}$ bağlamda, emeğe finans ve sermayeye davranıldığından çok farklı bir şekilde davranılmıştır. Bankalar bu durumda kazançlı çıkarken, emek büyük oranda zarar görmüştür (Griffith-Jones ve Jolly, 2013:50).

1980'lerden beri azgelişmiş ülkelerde farklı adlarla uygulanan kemer sıkma politikaları günümüzde Euro bölgesi için kriz sonrasında gündeme gelmiştir. "Diktatörlüğün yeni tipi" olarak adlandırılan bu yeni rejim, kemer sıkma politikaları ile toplumu ve işçileri disiplin altına alarak ekonomik güvensizliğin genelleştirilmesi, finansal desteklerin azaltılması ve sosyal programların tasfiye edilmesi anlamına gelmektedir (Bougrine, 2012:120).

\section{III) DURGUNLUK DÖNEMINDE KEMER SIKMA}

\section{POLITIKIKALARININ YARATTIĞI TEHLIKKE: MALİ TUZAK}

Keynesyen yaklaşım durgunluk döneminde değil, genişleme döneminde kemer sıkma politikalarının uygulanması gerektiğini savunmuştur. Çünkü kemer sıkma politikaları ekonomi durgunluk döneminde iken bir kısır döngüye sebep olmaktadır. Bütçe açıklarını azaltmaya yönelik politikalar nedeniyle büyümenin yavaşlaması sonucu vergi gelirleri azalıp, transfer harcamaları artacağı için artan bütçe açıkları nedeniyle daha fazla kemer sıkma ihtiyacı ortaya çıkmaktadır (Calcagno, 2012; Krugman, 2012). Bu durum devlet ile hane halkının davranışlarını bir tutmaktan kaynaklanmaktadır. Hane halkı harcamalarını azalttığında tasarruflarını artırabilir, bu davranışının hane halkı geliri üzerinde olumsuz bir etkisi söz konusu değildir. Ancak devlet daha az harcama yaptığında, eğer ekonomi durgunluk döneminde ise bu, gelirin de azalacağı anlamına geleceği için takiben vergi gelirlerinin azalmasına, transfer 
harcamalarının ve işsizliğin artmasına neden olmaktadır. Ekonominin zayıf olduğu dönemlerde maliye politikasının rolünü ve fonksiyonunu yanlış anlamaktan kaynaklanan ve kendi kendini besleyen bu ekonomik daralma sarmalı mali tuzak (fiscal trap) olarak adlandırılmaktadır (Hannsgen ve Papadimitriou, 2012; Palley, 2009; UNCTAD, 2011).

\section{Şekil:1 Mali Tuzak}

Harcama Kesintileri Vergi Artşlan

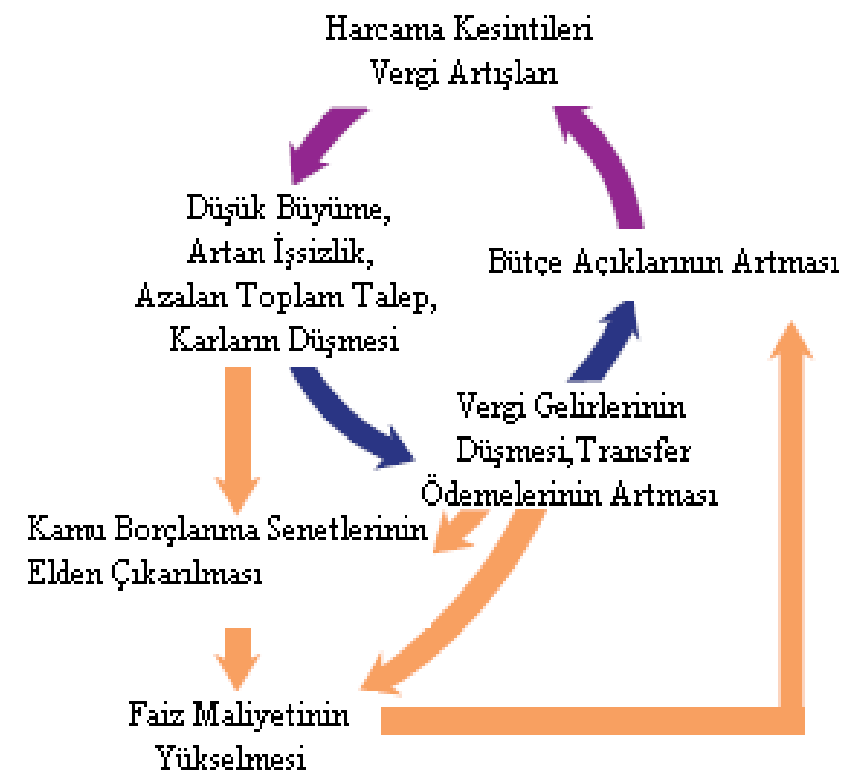

Kaynak: Hannsgen ve Papadimitriou, 2012

Mali tuzak, basit tuzak ve büyük mali tuzak olarak iki aşamada incelenebilir. Basit mali tuzak şekilde koyu renkli oklarla gösterilmektedir. Kriz nedeniyle uygulanan canlandırma paketleri ve finansal sektörü kurtarma operasyonları sonucu özel borçların kamu borcuna dönüştürülmesiyle bütçe açıkları artmakta, kamu borcunun/GSYİH'ya oranı yükselmektedir. Bütçe açıklarını kapatmak, ekonomide artan kamu sektörü payını düşürmek için mali canlandırmadan vazgeçilmesi, harcama kesintileri ve vergi artışlarına gidilmesi ise büyümeyi yavaşlatırken, işsizliğin artmasına, toplam talebin azalmasına ve karların düşmesine sebep olmaktadır. Alttaki okların gösterdiği gibi düşük veya negatif büyüme oranları ise, bir yandan kamu gelirlerinin azalmasına, diğer yandan transfer harcamalarının artmasına yol açarak bütçe açıklarını daha da artırmak suretiyle basit mali tuzağın kısır döngüsünü pekiştirmektedir. 
Basit mali tuzak, bağımsız para sisteminin yokluğunda daha kötü sonuçlar yaratabilmekte, büyük mali tuzağa dönüşebilmektedir. Düşük büyüme ve yüksek işsizlik, azalan vergi gelirleri ve artan transfer harcamaları sonucu devletin borçlarını ödeyemeyeceği korkusuyla kamu borçlanma senetlerinin elden çıarılması, faiz maliyetinin yükselmesine neden olarak hem faiz ödemelerini hem de anapara ödemelerini artırmaktadır. Borç servis ödemelerindeki artış ise bütçe açığını daha da artırmaktadır. Açık renkli oklarla gösterilen bu durum büyük mali tuzak olarak ifade edilmektedir (Hannsgen ve Papadimitriou, 2012:5).

Büyük mali tuzak esasen metalist sistemin geçerli olduğu ekonomilerde ortaya çıkmaktadır. Çünkü mali problemler metalist parasal sistemlerde ve chartalist parasal sistemlerde farklılaşmaktadır ${ }^{1}$. Metalist sistemde para arzı bazı $d$ lş faktörler tarafından kısıtlanmaktadır. Söz konusu kısıt, paranın arzı sınırlı altın ya da gümüş gibi madenlere dayalı olarak artırılması durumunda ya da devletin para basma yetkisinin denk bütçe yasaları, Maastricht rejimi veya sabit döviz kuru hedefi ile sınırlandırılması durumunda ortaya çıkmaktadır. Oysa Chartalist ya da vergiye dayalı para sisteminde ise para arzına ilişkin herhangi bir kısit söz konusu değildir. Bu sisteme göre esnek döviz kuru uygulandığı durumda kendi parasını basabilen bir devlet için kendi parası cinsinden borçlarını ödeyebilme gücü üzerinde durulması gerekmeyen, önemsiz bir konudur. Bu özgürlük, maliye politikasının tam istihdamın sağlanması için yönlendirilebilmesine olanak sağlamaktadır (Tcherneva, 2006; Wray, 2003; Göker, 2013a).

\section{IV) AVRUPA BİRLİ̆́íNDE KRİZ}

Kriz Avrupa Birliğinde tüm ülkelerde özellikle 2009 yılında büyüme oranlarında ciddi bir azalma, işsizlik oranlarında hızlı bir artış olarak etkisini göstermiştir. Ancak krizden çıkış sürecinde çevre ülkelerin artan borç stokları ve kamu açıkları, $A B D$ krizinin çevre ülkeler merkezli $A B$ krizine dönüşmesine neden olmuştur. Kriz, üye ülkelerin ödemeler dengesini bozarken, parasal birlik nedeniyle ülkelerin ulusal paralarının maliye politikasından ayrıştırılmış olması- bütün üyelerin avroyu kullanması fakat her bir ülkenin kendi maliye politikasından sorumlu olması- krizin derinleşmesinde önemli bir etken olmuştur (Wray, 2012).

Kriz nedeniyle artan borçlar İspanya ve İrlanda'da özel sektörden, esas olarak gayrimenkul sektöründen kaynaklanmaktadır. Bankaları kurtarma operasyonu nedeniyle özel borç kamusal borca dönüşmüştür. Portekiz, İtalya ve Yunanistan'da ise borç, kamu borcu niteliğindedir (Semmler ve Semmler,

\footnotetext{
${ }^{1}$ Ayrıntılı bilgi için bkz. Göker (2013b)
} 
2013). Portekiz, İtalya ve Yunanistan'da kriz öncesinde de borç oranı yüksek olmakla birlikte kriz sonrasında tüm çevre ülkelerde borç oranı artmıştır. Tablo-1, AB içinde krizden en fazla etkilenen çevre ülkeleri Yunanistan, İspanya, Portekiz, İtalya ve İrlanda'nın (GIPSI) kriz öncesi ve sonrasındaki kamu dengelerini ve brüt borçlarını göstermektedir. Buna göre, kriz öncesinde 2007 yılına bakıldığında Yunanistan hariç, diğer ülkelerin kamu dengelerinin kötü olmadığı söylenebilir. İrlanda ve İspanya'da kamu fazlası mevcuttur, İtalya ise \%-1,6'l1k oranıyla Maastricht Kriterlerinin altındadır. Ancak krizden sonra tüm ülkelerde kamu dengesi ciddi ölçüde bozulmuştur.

Kamu borcunun GSYİH'ya oranına bakıldığında, İrlanda ve İspanya'nın kriz öncesinde borç yükünün Maastrich kriterinin çok altında olduğu, fakat krizi izleyen beş yıl içinde bu ülkelerin kamu borcunun GSYİH'ya oranının hızla arttığı görülmektedir. Yunanistan ve İtalya ise kronik kamu borç sorunu yaşayan ülkelerdir. Bu iki ülkede kriz öncesi \%100'lere ulaşan kamu borcunun, kriz sonrasında önemli oranda artış gösterdiği gözlenmektedir. Portekiz'de ise kriz öncesinde \%70'lere yaklaşan oran, kriz sonrasında artarak \%120’lere yükselmiştir.

Tablo 2: AB Çevre Ülkelerinde Brüt Kamu Borcu ve

Kamu Açık/ Fazlası (GSYIH \% olarak)

\begin{tabular}{|c|c|c|c|c|c|c|c|c|c|c|}
\hline Yillar & \multicolumn{2}{|c|}{ Yunanistan } & \multicolumn{2}{|c|}{ İspanya } & \multicolumn{2}{|c|}{ Portekiz } & \multicolumn{2}{|l|}{ İtalya } & \multicolumn{2}{|c|}{ İrlanda } \\
\hline & $\begin{array}{l}\text { Brüt } \\
\text { Kamu } \\
\text { Borcu }\end{array}$ & $\begin{array}{l}\text { Kamu } \\
\text { Dengesi }\end{array}$ & $\begin{array}{l}\text { Brüt } \\
\text { Kamu } \\
\text { Borcu }\end{array}$ & $\begin{array}{l}\text { Kamu } \\
\text { Dengesi }\end{array}$ & $\begin{array}{l}\text { Brüt } \\
\text { Kamu } \\
\text { Borcu }\end{array}$ & $\begin{array}{l}\text { Kamu } \\
\text { Dengesi }\end{array}$ & $\begin{array}{l}\text { Brüt Kamu } \\
\text { Borcu }\end{array}$ & $\begin{array}{l}\text { Kamu } \\
\text { Dengesi }\end{array}$ & $\begin{array}{l}\text { Brüt } \\
\text { Kamu } \\
\text { Borcu }\end{array}$ & $\begin{array}{l}\text { Kamu } \\
\text { Dengesi }\end{array}$ \\
\hline 2003 & 97,5 & $-5,6$ & 48,8 & $-0,3$ & 59,4 & $-3,7$ & 103,8 & $-3,6$ & 30,7 & 0,4 \\
\hline 2004 & 98,9 & $-7,5$ & 46,3 & $-0,1$ & 61,9 & $-4,0$ & 103,6 & $-3,5$ & 29,5 & 1,4 \\
\hline 2005 & 101,2 & $-5,2$ & 43,2 & 1,3 & 67,7 & $-6,5$ & 105,7 & $-4,4$ & 27,3 & 1,6 \\
\hline 2006 & 107,5 & $-5,7$ & 39,7 & 2,4 & 69,4 & $-4,6$ & 106,2 & $-3,4$ & 24,6 & 2,9 \\
\hline 2007 & 107,2 & $-6,5$ & 36,3 & 2,0 & 68,4 & $-3,1$ & 103,3 & $-1,6$ & 25,1 & 0,2 \\
\hline 2008 & 112,9 & $-9,8$ & 40,2 & $-4,5$ & 71,7 & $-3,6$ & 106,1 & $-2,7$ & 44,5 & $-7,4$ \\
\hline 2009 & 129,7 & $-15,7$ & 53,9 & $-11,1$ & 83,7 & $-10,2$ & 116,5 & $-5,5$ & 64,8 & $-13,7$ \\
\hline 2010 & 148,3 & $-10,7$ & 61,5 & $-9,6$ & 94,0 & $-9,8$ & 119,4 & $-4,5$ & 92,1 & $-30,6$ \\
\hline 2011 & 170,3 & $-9,5$ & 69,3 & $-9,6$ & 108,3 & $-4,3$ & 120,8 & $-3,8$ & 106,4 & $-13,1$ \\
\hline 2012 & 157,0 & $-9,0$ & 84,1 & $-10,6$ & 123,6 & $-6,4$ & 127,0 & $-3,0$ & 117,6 & $-8,2$ \\
\hline
\end{tabular}

Kaynak: http://www.oecd.org/statistics/

http://epp.eurostat.ec.europa.eu/tgm/web/

Kriz sonrasında artan bütçe açıkları ve kamu borçları nedeniyle çevre ülkelere, Troyka tarafından (Avrupa Merkez Bankasi, IMF ve Avrupa Komisyonu) harcama kesintileri ve vergi artışlarına dayanan, emek piyasasının esnekleştirilmesini hedefleyen, sağlık, eğitim ve sosyal güvenlik 
düzenlemelerini ve özelleştirmeleri içeren kemer sıkma politikaları dayatılmıştır. Örneğin bu çerçevede Yunanistan'da 30000 kamu işçisi işten çıkarılmış, 1200 avrodan fazla olan emekli maaşları \%20 azaltılmış, 50 milyar avro gelir hedefleyen özelleştirme programları yürürlüğe konmuştur. Portekiz'de ise 2011 yılında kamu ücretlerinde ve emekli aylıklarında \%5 kesinti, 2012-13 yılları arasında ise \% 14 kesinti uygulanması planlanmış, gazelektrik gibi zorunlu mallarda KDV oranı \%18'e çıkartılmıştır. 5 milyar avro gelir sağlaması öngörülen özelleştirme uygulamalarının yanı sıra, işsizlik yardımı ve diğer sosyal yardımlarda kesintiye gidilirken emek piyasasının esnekleştirilmesine hız verilmiştir (Lapavitsas vd., 2011).

$\mathrm{Bu}$ politikaların temel amacı maliyeti ne olursa olsun borçların geri ödenmesini sağlamak, böylece bankaları ve tahvil sahiplerini emek aleyhine dengeyi değiştirerek korumaktır. Kriz çevre ülkelerinin rekabet gücünün azalmasıyla birlikte 2000'li yıllarda aşırı finansal genişlemeden çıkmış olmasına rağmen, krizden çıkmanın yükü kamu kesimine ve esas olarak emek piyasasına yansıtılmıştır (Onaran, 2010).

\section{A) Avro Bölgesindeki Dengesizlikler}

Birlik içinde, üye ülkeler arasındaki maliyet farklılıkları döviz kuru değiştirilerek düzeltilemeyeceği için her bir ülkedeki ücretlerin ve fiyatların uygun bir şekilde ayarlanması önemli olmaktadır. Bu amaçla Avrupa Merkez Bankası $\mathrm{AB}$ için ortak enflasyon hedefini yaklaşık \%2 olarak belirlemiştir. Böylece Birlik içindeki ülkelerin her birinde nominal ücretlerin, ortak enflasyon hedefi ve ulusal verimlilik artışı toplamından daha büyük olamayacağı, böylece orta ve uzun dönemde birim emek maliyeti ve ulusal enflasyon oranlarının enflasyon hedefine yaklaşması ile üye ülkeler arasında maliyet farklılıklarının ortadan kalkması öngörülmüştür (Lapavitsas vd., 2011).

Ancak bu öngörü gerçekleşmemiştir. Merkez ve çevre ülkeler arasında ortaya çıkan önemli maliyet farklılıkları ülkelerin rekabet güçlerini ve sonuçta da cari dengelerini etkilemiştir. Bu noktada merkez ülkelerden özellikle Almanya ile çevre ülkeleri, GIPSİ arasındaki ilişkilerin üzerinde durulması gerekir. Almanya, II. Dünya Savaşı sonrasında uyguladığı fiyat istikrarını hedefleyen makro politikalar ile ihracata dayalı büyüme modelini Birliğe girdikten sonra da devam ettirmiştir. Bu çerçevede üretimi Doğu Avrupa ülkelerine veya diğer düşük ücretli bölgelere taşıma tehdidi ile sendikaları ikna ederek nominal ücret artışlarını baskı altına almış ve böylece birim emek maliyetlerinin 1999'tan bu yana yatay seyretmesini sağlamıştır. Birliğin tamamı için \%2 enflasyon hedefi tutturulmasına rağmen, Almanya ortak enflasyon hedefinin altında kalarak rekabet avantajını artırmıştır çünkü düşük enflasyon oranı Alman ihraç mallarının değerini düşürerek, ihracatçıların 
karlarına ve yurt dışı satışlara yapılan zımni bir sübvansiyon etkisi yaratmıştır. Diğer yandan hem ücretlerin baskı altına alınması ile artan kurum karları nedeniyle, hem de düşük enflasyon oranının reel faizleri artırması ile tasarruflar da artmıştır. Sonuçta ülkenin GSYİH, tüketim artışından daha hızlı büyürken, bütçe açıkları azalmış, dış fazlası artmıştır.

Almanya'nın 1999'dan önce GSYIH içinde \%30 olan ihracat payı, 2012 yılında \%50'ye çıkmıştır. Büyük bir ülke olarak komşularının hem bölgesel hem de küresel çapta pazar payını ele geçirerek, komşuyu fakirleştiren uygulamalarla bunu başarmıştır. Ücret artışlarını baskılayarak, ortak enflasyon hedefinden daha düşük bir enflasyonla ulaşılan bu başarı, ticaret ortaklarının karşı tepki vermemesi ile mümkün olabilmiştir.

1999 yılından itibaren GIPSİ'de ise nominal ücret artışlarının, ortak enflasyon hedefi ve verimlilik artışı toplamını küçük ama istikrarlı bir şekilde aştığı görülmektedir. Bu ülkelerde birim emek maliyetindeki artış göreli olarak küçük olsa da bu küçük yıllık farklar zaman içinde büyük bir fark yaratmıştır. İlk on yıl tamamlandığında Almanya ile GIPSI arasındaki maliyet ve fiyat farkı \%25, Almanya ile Fransa arasında \%15 olmuştur. Diğer bir deyişlle ulusal paralar olmasa da Almanya'nın reel döviz kuru önemli ölçüde değer kaybetmiş, farklı birim emek maliyetleri önemli fiyat farklılıkları yaratmıştır. Alman ihracatçıların kar marjı değişmezken, 1999 y1lında AB'ne üye tüm ülkelerde aynı fiyattan satılan bir mal, 2010 yılında Almanya'da, diğer üye ülkelere göre \%25 daha ucuz satılır hale gelmiştir. (Flassbeck ve Lapavitsas, 2013).

Ancak yurt içi kredilerdeki hızlı artış bu ülkelerin rekabet gücünün azalmasını gizlemiştir. Çünkü Birlik içinde ortak bir faiz oranı belirlenmiş olması bu ülkelerde faiz oranlarının düşmesine yol açmıştır. Ancak enflasyon oranları da aynı hızla düşmediği için reel faiz oranlarının düşmesi hatta negatif olması, kredilerin hızla artmasının ve ticari bankacılığın gelişmesinin önünü açmıştır. Artan krediler tüketimin devam etmesini sağlarken, rekabet gücünün azalmasından kaynaklı cari işlemler açıklarının da ucuz bir şekilde finanse edilmesini kolaylaştırmıştır. Krediler aynı zamanda gayrimenkul gibi bazı alanlarda yatırımları da teşvik etmiştir. Özellikle İrlanda ve İspanya'da gayrimenkul fiyatları artarak büyük balonların oluşmasına yol açarken, artan dış borçlar cari işlem fazlası veren ülkelerin, Almanya ve Fransa'nın bankaları tarafından karşılanmıştır. Ancak borcun avro üzerinden olması sanki yurt içi borçmuş gibi yanlış bir algılamaya yol açmıştır. Borç oranı arttıkça 2009 yılından sonra uluslar arası piyasalardan bu ülkelerin borç bulmasının zorlaşmasının nedeni borç verenlerin, tüm avro üzerinden borçların aynı olmadığını, bir avro Alman kamu borcunun, bir avro Yunan kamu borcundan daha değerli olduğunu fark etmesinden kaynaklanmaktadır. 
2009 y1lından sonra Avro bölgesinde çevre ülkeleri için üç farklı krizden söz edilebilir: borç krizi, durgunluk nedeniyle yurt içi talep krizi ve cari işlemler krizi. $\mathrm{Bu}$ dönemde Troyka tarafindan bu ülkelere dayatılan kemer sıkma politikaları borç krizine ve cari işlemler krizine odaklanmıştır. Ancak bu uygulamalar 2. tür krizi; durgunluk nedeniyle yurt içi talep krizini derinleştirerek, şiddetli işsizlik ve gelir yetersizliklerine yol açmakta mali tuzağa zemin hazırlamaktadır.

Kemer sıkma politikaları ile ihracat payı düşük fakat cari işlemler açığı büyük olan çevre ülkelerin, zımni olarak aşırı değerli para nedeniyle ortaya çıkan finansman problemleri, birim emek maliyeti düşürülerek rekabet gücünün artırılması ile çözülmek istenmektedir. Bu amaçla ücretlerin düşürülmesi "iç devalüasyon" olarak tanımlanmaktadır. Ücretlerdeki azalmanın yarattığı deflasyonist etki, borcun nominal değeri değişmezken tüm gelir akımı azaldığı için hem iç hem de dış borçların reel değerinin artmasına sebep olmaktadır. Ancak iç devalüasyondan beklenen, emek piyasasının deregülasyonu; ücretlerin düşürülmesi, çalışanları koruyan düzenlemelerin kaldırılması ya da azaltılması yoluyla birim emek maliyetinin düşürülmesi ve böylece rekabet gücünün artmasıyla ihracatın, toplam talebin ve üretimin artmas1, cari dengenin düzelmesidir ${ }^{2}$ (Bibow, 2012). Fakat bu görüş yapısal ya da fiyat dışı rekabet gücüne ilişkin durumları (ihraç mallarının çeşidi, coğrafik uyumu, firmaların büyüklüğü, ürünlerin çeşidi ve kalitesi, işgücünün eğitim düzeyi, endüstriyel ilişkilerin biçimi gibi), ücretlerdeki azalmanın yurt içi talebe etkisini dikkate almamaktadır. Bu nedenle ihracat artışından önce yurt içi talebi ve üretimi olumsuz etkileyerek ekonomide uzun süre durgunluğa sebep olmaktadır.

\footnotetext{
${ }^{2}$ Goldman Sachs'ın çalışmasına göre sürdürülebilir dış denge için gerekli fiyat ayarlaması Portekiz için \%35 değer kaybı, Yunanistan için \%30, İspanya ve Fransa için \%20, İtalya için \%10-15 değer kaybı, buna karşıllık Almanya'da \%25 değerlenme gerektirmektedir (Nielsen, 2012:2).
} 
Tablo: 3 Seçilmiş AB ülkelerinde Reel GSYİH Büyüme Oranı ve İşsizlik Oranı

\begin{tabular}{|c|c|c|c|c|c|c|c|c|c|c|}
\hline Y1llar & \multicolumn{2}{|c|}{ Yunanistan } & \multicolumn{2}{c|}{ İtalya } & \multicolumn{2}{c|}{ İspanya } & \multicolumn{2}{c|}{ Almanya } & \multicolumn{2}{c|}{ Avro Bölgesi } \\
\hline & $\mathrm{BO}$ & $\dot{\mathrm{I} O}$ & $\mathrm{BO}$ & $\dot{\mathrm{I} O}$ & $\mathrm{BO}$ & IO & $\mathrm{BO}$ & İO & BO & İO \\
\hline $1995-2004$ & 3,7 & 10,5 & 1,6 & 10,0 & 3,7 & 15,8 & 1,3 & 9,0 & 2,2 & 9,6 \\
\hline 2005 & 2,3 & 9,9 & 0,9 & 7,7 & 3,6 & 9,2 & 0,8 & 11,2 & 1,7 & 9,2 \\
\hline 2006 & 5,5 & 8,9 & 2,2 & 6,8 & 4,1 & 8,5 & 3,9 & 10,2 & 3,2 & 8,5 \\
\hline 2007 & 3,5 & 8,3 & 1,7 & 6,1 & 3,5 & 8,3 & 3,4 & 8,8 & 3,0 & 7,6 \\
\hline 2008 & $-0,2$ & 7,7 & $-1,2$ & 6,8 & 0,9 & 11,3 & 0,8 & 7,6 & 0,4 & 7,6 \\
\hline 2009 & $-3,1$ & 9,5 & $-5,5$ & 7,8 & $-3,7$ & 18,0 & $-5,1$ & 7,7 & $-4,4$ & 9,6 \\
\hline 2010 & $-4,9$ & 12,5 & 1,7 & 8,4 & $-0,3$ & 20,1 & 4,0 & 7,1 & 2,0 & 10,1 \\
\hline 2011 & $-7,1$ & 17,7 & 0,4 & 8,4 & 0,4 & 21,7 & 3,1 & 6,0 & 1,4 & 10,2 \\
\hline 2012 & $-6,4$ & 24,2 & $-2,4$ & 10,7 & $-1,4$ & 25,0 & 0,9 & 5,5 & $-0,6$ & 11,4 \\
\hline $2013^{*}$ & $-4,2$ & 27,0 & $-1,5$ & 12,5 & $-1,6$ & 26,9 & 0,6 & 5,6 & $-0,3$ & 12,3 \\
\hline $2014 *$ & 0,6 & 26,0 & 0,5 & 12,4 & 0,7 & 26,7 & 1,5 & 5,5 & 1,1 & 12,2 \\
\hline
\end{tabular}

*Tahmin

BO: büyüme oranı, İO: işsizlik oranını göstermektedir.

Kaynak: IMF (2013) World Economic Outlook

2010 yılından itibaren henüz ekonomilerde cılız bir iyileșmenin sağlandığı dönemde uygulanan kemer sıkma politikaları çevre ülkelerin mali dengelerini ve makroekonomik performanslarını olumsuz etkilemiştir. Tablo2'de görüldüğü gibi büyüme oranları düşerken, işsizlik hızla artmıştır. Hedeflenenin aksine bütçe açıkları devam ederken, borç oranları artmış (bkz Tablo-1), çevre ülkeler mali tuzağa sürüklenmiştir. Çünkü kemer sıkma politikaları borç oranını, borç stoku/GSYİH, azaltmak için payı düşürmeyi hedeflemekte ancak aynı zamanda paydayı da olumsuz etkiledikleri için başarılı olamamaktadır.

$$
\Delta \text { borç stoku/GSYIH }_{\mathrm{t}}={\text { birincil } \text { açık }_{\mathrm{t}}+(\mathrm{r}-\mathrm{g}) \text { borç stoku/GSYIH }}_{\mathrm{t}-1}
$$

Borç oranında bu dönem ortaya çıkan değișiklik, bir önceki dönem borç oranının, borç faiz oranı ve büyüme oranı arasındaki fark ile çarpımının, birincil açı ile toplamına eşittir. Bu nedenle borç oranını düşürmek, birincil fazla (faiz dışı fazla) vermenin yanı sıra büyüme oranının borç faiz oranından yüksek olmasını da (g>r) gerektirmektedir. Ancak bağımsız merkez bankalarına sahip olmayan çevre ülkelerin risk priminin yüksekliği nedeniyle yüksek faiz oranlarından borçlanmak zorunda kalmaları, kemer sıkma politikalarının büyüme oranına olumsuz etkisi ile birleşince, borç oranı azalmak yerine artmaktadır (Bernstein, 2013:54). 


\section{B) Çevre Ülkelerde Borç Oranı Nasıl Düşürülebilir?}

Çevre ülkelerin borç oranlarını düşürebilmeleri için iki önemli gereklilikten biri borçlarını düşük faiz oranları ile çevirebilmeleri, diğeri ve daha önemli olanı ise dış talebin mutlaka artmasıdır. Ancak ülkelerin ihtiyaçlarını dikkate alarak faiz oranlarını düzenleyebilen bir merkez bankasının yokluğu, Yunanistan örneğinde olduğu gibi ülkelerin yüksek faiz oranları ile borçlanmasına, dolayısıyla da borç oranının artmasına yol açmaktadır. Diğer yandan borçlu bir ülke ancak fazla veren ülke, açık veren ülkenin fazla veren ülke olmasına izin verirse borçlarını ödeyebilir. $\mathrm{Bu}$ da ücretlerin veya döviz kurunun düzenlenmesiyle fiyatların düşürülmesi ve böylece rekabet gücünün artması ile mümkün olabilir. Borçlu ülkeler borçlarını ödemek için daha az tüketmeli, daha fazla tasarruf etmeli ve daha fazla vergi ödemelidir. Keynesyen yaklaşıma göre bu ancak gelirin değişmemesi halinde mümkün olabilir, daha az tükettiklerinde yabanc1lara daha fazla satabilmeleri durumunda borçlarını ödeyebilirler. Bu sağlanamaz ise talep azalır, işsizlik artar ve borç artmaya devam eder. Bu durumda tasarruf oranının artacağının garantisi de yoktur çünkü eğer dış talep yetersiz olursa gelirdeki düşme, tasarruflardaki artıştan daha fazla olabilir.

Ulusal gelirin toplam harcamalar tarafindan belirlendiği toplam gelir (Y) özdeşliğinde toplam harcamalar hane halkının tüketim kararları (C), iş âleminin yatırım kararları (I), net kamu harcamaları (G-T), net ihracat (X-M) tarafından belirlenmektedir. Her ekonomik birim kazandığından daha fazlasını harcayabilir fakat bu ekonominin geneli için geçerli değildir; başka bir sektörde telafi edici bir değişiklik ya da gelir düzeyinde değişikliği gerektirir. Keynesyen yaklaşıma göre toplam talep-gelir eşitliği aşağıdaki gibidir;

$$
\begin{aligned}
& \mathrm{Y}=\mathrm{C}+\mathrm{I}+(\mathrm{G}-\mathrm{T})+(\mathrm{X}-\mathrm{M}) \\
& \mathrm{C}=\mathrm{Y}-\mathrm{S} \\
& \mathrm{Y}=(\mathrm{Y}-\mathrm{S})+\mathrm{I}+(\mathrm{G}-\mathrm{T})+(\mathrm{X}-\mathrm{M}) \\
& 0=(\mathrm{I}-\mathrm{S})+(\mathrm{G}-\mathrm{T})+(\mathrm{X}-\mathrm{M})
\end{aligned}
$$

Buradan bir sektörün net pozisyonu, diğer iki sektörün pozisyonuna göre belirleneceği için;

$$
\begin{aligned}
& (\mathrm{S}-\mathrm{I})=(\mathrm{G}-\mathrm{T})+(\mathrm{X}-\mathrm{M}) \\
& (\mathrm{S}-\mathrm{I})=(\mathrm{X}-\mathrm{M})-(\mathrm{T}-\mathrm{G})
\end{aligned}
$$

yazılabilir. Son eşitliğe göre özel sektörün tasarruflarını artırması ( $\mathrm{S}>\mathrm{I})$, ancak eşitliğin sağ tarafinın pozitif olması ile mümkündür. Borçların geri ödenebilmesi için kamunun da bütçe fazlası verdiği durumda $(T>G)$ eşitliğin 
sağ tarafının pozitif olması ancak $(\mathrm{X}-\mathrm{M})>(\mathrm{T}-\mathrm{G})$ olması ile mümkün olabilir. Dolayısıyla yurt içi tasarrufların, gelir düzeyi azalmadan artırılması arzulanıyorsa dış sektör önemli bir belirleyici olmaktadır. Eşitlikten özel sektör ile kamu sektörünün borç ödeme gücünün belirlenmesinde, dış fazla verilebilmesinin hayati öneme sahip olduğu görülmektedir (Kregel, 2011).

Kemer sıkma politikaları ile Troyka çevre ülkelere Almanya'yı örnek göstermekte, Almanya gibi birim emek maliyetini düşürerek ihracatlarını artırmalarını istemektedir. Bu noktada çevre ülkeler, özellikle de Yunanistan'ın yapması gereken $\mathrm{AB}$ dışındaki ülkelere ve Birlik içindeki ülkelere ihracatını artırmaktır. Ancak bir yandan döviz kurunu değiştiremeyeceği için $A B$ dışındaki ülkelere ihracatını artırma olanağı kısıtlıdır, diğer yandan da Birliğe üye ülkelerin hepsi ücretleri düşürerek diş talebe dayalı büyümeye çalışırken, Birlik içinde dış talep artışının nasıl sağlanacağı belirsizdir. $\mathrm{Bu}$ nedenle Almanya'nın merkantilist politikalarından vazgeçerek ücretleri yükseltmesi, çevre ülkeler için dış talep yaratması, açık veren ülkelerin fazla vermesini mümkün kılmas1 gereklidir (Flassbeck vd., 2013; Stockhammer, 2011; Lapavitsas vd., 2010; 2011).

\section{SONUÇ}

2008 küresel finansal krizi, ABD'de konut balonunun patlamasıyla birlikte finansal sistemde ortaya çıkmış, etkileri kısa dürede başta $\mathrm{AB}$ ülkeleri olmak üzere dünyanın geri kalanına hızla yayılmışıı. Finansal sistemlerde yaşanan panik karşısında hükümetler ve merkez bankaları, finansal sektöre büyük miktarlarda likit kaynak transfer etme yolunu tercih etmiştir. Bu durum ülkelerin kamu açıklarının ve borçlarının genel olarak artmasına yol açmıştır. Dolayısıyla, bu kurtarma stratejilerinin uygulanmasiyla ekonomilerde gözlenen göreli canlanmalar krizin neden ortaya çıktığı sorusunu arka plana itmiş, yüksek kamu borç ve kamu açıkları bir sorun olarak gündeme gelmiştir. $\mathrm{Bu}$ durum kamu borçları ve açıkları karşısında hükümetleri finanse etme rolünü krizi yaratan finansal sektöre bırakılmasına neden olmuştur.

Kriz Avrupa Birliğinde tüm ülkelerde özellikle 2009 yılında büyüme oranlarında ciddi bir azalma, işsizlik oranlarında hızlı bir artış olarak etkisini göstermiştir. Ancak krizden çıkış sürecinde çevre ülkelerin artan borç stokları ve kamu açıkları, $A B D$ krizinin çevre ülkeler merkezli $A B$ krizine dönüşmesine neden olmuştur.

2009 yılından sonra Avro bölgesinde çevre ülkeleri için üç farklı krizden söz edilebilir: borç krizi, durgunluk nedeniyle yurt içi talep krizi ve cari işlemler krizi. $\mathrm{Bu}$ dönemde Troyka tarafindan bu ülkelere dayatılan kemer sıkma politikaları borç krizine ve cari işlemler krizine odaklanmıştır. Ancak bu 
uygulamalar 2. tür krizi; durgunluk nedeniyle yurt içi talep krizini derinleştirerek, şiddetli işsizlik ve gelir yetersizliklerine yol açmakta mali tuzağa zemin hazırlamaktadır. Bununla birlikte, kriz sonrasında artan bütçe açıkları ve kamu borçları nedeniyle çevre ülkelere, Troyka tarafindan harcama kesintileri ve vergi artışlarına dayanan, emek piyasasının esnekleştirilmesini hedefleyen, sağlık, eğitim ve sosyal güvenlik düzenlemelerini ve özelleştirmeleri içeren kemer sıkma politikaları dayatılmıştır.

AB ülkelerinin büyüme performanslarına ait 2013 yılında açıklanan 3. Çeyrek rakamları büyümede henüz ciddi bir canlanma eğiliminin gözlenmediğini göstermektedir. Eurostat'ın açıkladığı üçüncü çeyrek büyüme rakamları ikinci tahmin raporuna göre 28 üyeli birlik bir önceki çeyreğe göre yüzde 0,2 oranında büyümüştür. Bu oran Euro Bölgesi için yüzde 0,1 olarak gerçekleşmiştir. Üçüncü çeyrekte AB'nin en fazla büyüyen ekonomileri \%1,6 ile Romanya, \%1,2 ile Letonya olurken, Fransa ve İtalya gibi ekonomiler \%0,1 oranında daralmıştır.

$A B$ 'de çevre ülkelerde uygulanan kemer sıkma politikalarının amacı kriz sonucunda artan bütçe açıkları ve kamu borç oranının düşürülmesidir. Ancak ekonomilerin durgunluk döneminde yüksek işsizlik oranlarına rağmen uygulanan bu politikalar başarısız olmuş, büyüme oranlarının düşmesine, işsizlik oranlarının artmasına, kamu borç oranının daha da yükselmesine yol açmış, ülkeleri mali tuzağa itmiştir. Aslında makro politikaların hedefi borç oranını düşürmek yerine istihdam kayıplarını telafi etmek, işsizlik oranlarını düşürmek, yeni iş alanları yaratmak olmalıdır. 


\section{KAYNAKÇA}

ALBO, G. ve EVANS, B. (2012) "Kurtarma Stratejilerinden Çıkış Stratejilerine Geçiş: Kamuda Kemer S1kma Kavgası", Sosyalist Register 2011 Bu Defaki Kriz içinde, (Ed.) Panicth, L. G. Albo, ve V. Chibber, Yordam Kitap, İstanbul, ss. 310-335.

Recent

ALESINA, Alberto F. (2010) "Fiscal Adjustments: Lessons from http://scholar.harvard.edu/files/alesina/files/fiscaladjustments lessons-1.pdf (10.09.2013)

ALESINA, A. F., ARDAGNA, S. (1998) "Tales of Fiscal Contractions", Economic Policy, 27, pp.487-545

ALESINE, A. F., ARDAGNA, S. (2010) "Large Changes in Fiscal Policy: Taxes Versus Spending” NBER Working Paper, No.15438

BAKER, Dean (2010) "The Myth of Expansionary Fiscal Austerity" Center for Economic and Policy Research.

BAUM, A., M. POPLAWSKI-RIBEIRO, and A. WEBER (2012) "Fiscal Multipliers and the State of the Economy" Working Paper 12/286. International Monetary Fund. Aral1k

BERNSTEIN, Jared (2013) "Cyclical Doves, Structural Hawks (CDSH): Turning Fiscal Policy Right-Side Up Again", The Macroeconomics of the Fiscal Consolidation in the European Union, içinde (Ed.) Palley, T., and G.A.Horn Create Space Independent Publishing Platform.

BIBOW, Jörg (2012) “The Euro Debt Crisis and Germany's Euro Trilemma" Levy Economics Institute, WP, No.721

BLANCHARD, O., D. LEİGH (2013), "Growth Forecast Errors and Fiscal Multipliers", IMF Study,WP/13/1

BOUGRINE, Hassan (2012) "Fiscal Austerity, the Great Recession and the rise of new dictatorships" Review of Keynesian Economics, Autumn, pp.109-125.

BOYER, Robert (2012) "The Four Fallacies of Contemporary Austerity Policies: the Lost Keynesian Legacy" Cambridge Journal of Economics, 36, pp.283-312.

CALCAGNO, A. (2012) "Can Austerity work?" Review of Keynesian Economics, Autumn, pp.24-36. 
FLASSBECK, H., LAPAVITSAS, C. (2013) "The Systemic Crisis of the Euro-True Causes and Effective Therapies" www.networkideas.org/featart/may2013/fa17_Systemic_Crisis.htm (5.11.2013)

GÖKER, Zeliha (2013a) "Küresel Kriz Sonrası Maliye Politikalarında Değişim Ve Mali Tuzak Riski”, Çalışma ve Toplum Dergisi, 40.

GÖKER, Zeliha (2013b) "Vergiye Dayalı Para Yaklaşımı ve Fonksiyonel Maliye”, Vergi Dünyası Dergisi, 387, Kasım, ss.43-47

GRIFFITH-JONES, S., JOLLY, R. (2013) "Be Outraged by Austerity" Challange, Vol. 56. No.1, pp.46-60.

HANNSGEN, G., D. PAPADIMITRIOU (2012) "Fiscal Traps and Macro Policy After The Eurozone Crisis", Levy Economics Institute, Public Policy Brief, No.127.

IMF (2010) "Will It Hurt? Macroeconomic Effects of Fiscal Consolidation" Economic

Outlook, http://www.imf.org/external/pubs/ft/weo/2010/02/pdf/c3.pdf (11.8.2013)

IMF(2013) World Economic Outlook

JAYADEV, A., KONCZAL, M. (2010) "The Boom Not The Slump: The Right Time For Austerity", Roosevelt Institute, www.rooseveltınstıtute.org (14.Eylül 2013)

KREGEL, Jan (2011) 'Debtors' Crisis or Creditors' crisis? Who Pays fort he European Sovereign and Subprime Mortgage Losses?" Levy Economics Institute, Public Policy Brief, No.121. blog, 22 March.

KRUGMAN, Paul (2012) "Blunder of Blunders", The New York Times

LAPAVITSAS, C., A. KALTENBRUNNER, A., LINDO, D., MEADWAY, J., MICHELL, J., PAINCEIRA, J.P., PIRES, E., POWELL, J., STENFORS, A., TELES, N. AND VATIKIOTIS, L. (2011) "Breaking Up? A Route Out Of The Eurozone Crisis" $R M F$ Occasional Report 3. http://www.researchonmoneyandfinance.org/wp-

content/uploads/2011/11/Eurozone-Crisis-RMF-Report-3-Breaking-Up.pdf (22.10.2013)

LAPAVITSAS, C., KALTENBRUNNER, A., LINDO, D., MICHELL, J., PAINCEIRA, J.P., PIRES, E., POWELL, J., STENFORS, A. and N. TELES (2010) "Eurozone Crisis: Beggar Thyself and Thy Neighbour" $R M F$ Occasional Report 
http://researchonmoneyandfinance.org/media/reports/eurocrisis/fullreport.pdf (22.10.2013)

NIELSEN, L.H.W. (2012) "Achieving Fiscal and External Balance (Part 1): The Price Adjustment Required for External Sustainability." European Economics Analyst No. 12/01, March 15, Goldman Sachs.

ORTIZ, I., CUMMINS, M. (2013) "The Age of Austerity: A Review of Public Expenditures and Adjustmet Measures in 181 Countries" South Centre $W P$. www.policydialogue.org

PALLEY, Thomas (2009) “The Fiscal Austerity Trap" New American Contract Policy Paper, http://www.insightweb.it/web/files/Thomas_PalleyThe Fiscal Austerity Trap 0.pdf (01.10.2013)

PEROTTI, Roberto (2011) "The “Austerity Myth": Gain without Pain?" NBER Working Paper, No.17571

SEMMLER,W., SEMMLER, A. (2013) "The Macroeconomics of the Fiscal Consolidation in the European Union" http://papers.ssrn.com/sol3/papers.cfm?abstract_id=2320198 (8.12.2013)

STOCKHAMMER, Engelbert (2011) "Peripheral Europe's debt and German Wages: the Role of Wage Policy in the Euro Area," International Journal of Public Policy, Vol. 7(1/2/3), pp.83-96.

ONARAN, Özlem (2010) "Fiscal Crisis in Europe or a Crisis of Distribution?” PERI Working Paper No. 226

TCHERNEVA, R. Pavlina (2006) "Chartalism and the Tax-Driven Approach to Money", Handbook of Alternative Monetary Economics içinde (Ed.) Philip Arestis and Malcolm Sawyer, Elgar Publishing, London, pp.69-84.

UNCTAD (2011) Trade and Development Report, Post-Crisis Policy Challenges in the World Economy, United Nations Publications, New York ve Geneva.

ZEZZA, Gennaro (2012) "The Impact of Fiscal Austerity in the Eurozone" Review of Keynesian Economics, Autumn, pp.37-54.

WRAY, L. Randall (2003) Understanding Modern Money: The Key to Full Employment and Price Stability, London: Edward Elgar.

WRAY, L. Randall (2012) "MMT and the Euro: Current Account Imbalances and the Euro Crisis Part 2" http://www.economonitor.com/lrwray/2012/07/12/mmt-and-the-euro-arecurrent-account-imbalances-to-blame-for-the-euro-disaster-part-1/ $(16.12 .2013)$ 